\title{
Retomar o debate logo
}

\section{The debate must be resumed promptly}

\section{Hay que retomar con celeridad el debate}

\author{
Alba Maria Zaluar ${ }^{1, a}$ \\ azaluar1984@gmail.com | https://orcid.org/oooo-0001-6892-3176 \\ ${ }^{1}$ Universidade do Estado do Rio de Janeiro, Instituto de Estudos Sociais e Políticos. Rio de Janeiro, RJ, Brasil. \\ a Doutorado em Antropologia pela Universidade de São Paulo.
}

\section{Resumo}

A nota apresenta um histórico do debate público sobre violência e criminalidade e mostra a necessidade de retomar o debate ao seu nível anterior, tratando o tema não só como uma questão de segurança pública, mas também de saúde. Reafirma que é preciso enfrentar o contexto social em que jovens se matam mutuamente, que criam um inimigo odiado e desumanizado. Faz uma crítica à polarização em curso no país, na qual a possibilidade de ter compaixão pelo sofrimento do outro desapareceu. Sugere iniciativas que podem ajudar a enfrentar a disseminação do etos guerreiro, consolidando a segurança pública baseada na cidadania. E relembra que enfrentar a violência é enfrentar as assimetrias causadas por dominações autoritárias, seja pelo Estado, seja por facções criminosas.

Palavras-chave: Violência; Medo; Armas; Drogas; Policiais; Cidadania.

\begin{abstract}
The note shows the history of the public debate on violence and crime and the need to resume the debate at its previous level, addressing the topic not only as a matter of public safety but also the health problem. It reaffirms that it is necessary to address the social context where young people kill each other, creating a hated and dehumanized enemy. It criticizes the polarization in progress in the country, in which the possibility of having compassion for the suffering of the other disappeared. Initiatives that can help addressing the spread of the warrior ethos are suggested, consolidating public safety based on citizenship. Also, it recalls that facing violence is to confront the asymmetries caused by authoritarian dominations, whether by the state or by criminal factions.
\end{abstract}

Keywords: Violence; Fear; Guns; Drugs; Police officers; Citizenship. 


\section{Resumem}

La nota presenta un histórico del debate público sobre violencia y criminalidad y muestra la necesidad de retomar el debate a su nivel anterior, tratando el tema no sólo como un problema de seguridad pública, pero también de salud. Reafirma que es preciso enfrentar el contexto social en que los jóvenes se matan mutuamente, que crean un enemigo odiado y deshumanizado. Hace una crítica a la polarización en curso en el país, en la cual la posibilidad de tener compasión por el sufrimiento del otro desapareció. Sugiere iniciativas que pueden ayudar a enfrentar la diseminación del ethos guerrero, consolidando la seguridad pública basada en la ciudadanía. Y recuerda que enfrentar la violencia es enfrentar las asimetrías causadas por dominaciones autoritarias, tanto por el Estado, como por facciones criminosas.

Palabras clave: Violencia; Miedo; Armas de fuego; Drogas; Policía; Ciudadanía.

Contribuição dos autores: A autora é responsável por todo o texto.

Fontes de financiamento: Não houve.

Considerações éticas: Não há.

Agradecimentos/Contribuições adicionais: Não há.

Histórico do artigo: Submetido: 03.dez.2018 | Aceito: 04.dez.2018 | Publicado: 21.dez.2018.

Apresentação anterior: Não houve.

Licença CC BY-NC atribuição não comercial. Com essa licença é permitido acessar, baixar (download), copiar, imprimir, compartilhar, reutilizar e distribuir os artigos, desde que para uso não comercial e com a citação da fonte, conferindo os devidos créditos de autoria e menção à Reciis. Nesses casos, nenhuma permissão é necessária por parte dos autores ou dos editores.

O que está em questão hoje no debate público sobre a violência e a criminalidade? Simplificando uma extensa e diversificada polêmica entre muitos agentes opinativos, principalmente jornalistas transformados em especialistas em segurança pública e alguns cientistas sociais escolhidos como 'as fontes', o debate central durante o período eleitoral reduziu as questões à posse ou não de armas e à importância da repressão ou do uso da força para eliminar 'bandidos', protegendo juridicamente o policial que mata. É preciso retomar o nível anterior do debate, do qual sempre participei ativamente e que me mobiliza cada vez mais, de modo a superar a redução de problemas sociais complexos a uma questão de polícia, ainda por cima apenas repressiva e letal.

Como já afirmei em vários textos que escrevi ${ }^{1,2}$, observei nos anos 1970, durante o regime militar, que jovens que iniciavam carreiras no crime perceberam que assaltar bancos era muito arriscado e que o tráfico de drogas era mais fácil e lucrativo. Transformaram então a composição e a organização das chamadas 'bocas de fumo' no Rio de Janeiro, e das ‘biqueiras’ em São Paulo. Estudei, desde 1980, essa transformação no Rio de Janeiro. A Polícia Militar, já então encarregada do policiamento e da repressão, agia em favelas e conjuntos habitacionais com métodos usuais na época para coagir traficantes então independentes. Começara a dialética corrupção/manutenção do negócio/abuso da força policial/violação de direitos. Nos anos 1980, instalaram a lógica da guerra entre traficantes, reforçada pela rivalidade mortal entre os comandos fundados na prisão no final dos anos 1970, quando estes já se interessavam pelo tráfico como 
forma de financiar a organização. A corrida armamentista, para dissuadir os comandos rivais de invadir as favelas dominadas, exigiu a compra de cada vez mais armas de fogo modernas e letais, bem como o treinamento de jovens para as atividades guerreiras. Os traficantes do Rio de Janeiro se dividem hoje em três facções, grandes compradoras de armas pesadas em virtude dos conflitos armados entre elas ou de cada facção com as forças policiais. A trama das alianças, nunca definitivas, e das inimizades é complexa e cambiante. As bocas de fumo, que já haviam iniciado uma corrida armamentista para proteger os pontos de venda dentro das favelas desde 1978, tinham o dono da boca conhecido pelos vizinhos, ou seja, era uma 'cria' da favela. Esse caráter de pequeno negócio local, do varejo das drogas, baseado nas relações de reciprocidade dentro das favelas ou entre elas, vai marcar as facções cariocas que nunca chegaram a virar empresas modernas, nem mesmo depois de sua vinculação com os comandos.

Apesar de ser crítica da redução do combate ao crime à repressão policial, sem considerar a dissuasão e, principalmente, a prevenção, em todas as suas formas seguindo os direitos humanos (ou civis, pois estão na Constituição de 1988), considero, no entanto, um grave erro não considerar os riscos pessoais à integridade física, principalmente dos pobres periféricos e favelados, e as sérias ameaças à democracia no Brasil que decorrem do crime organizado em torno do tráfico de drogas, desenvolvido simultânea e paralelamente ao tráfico de armas e, mais tarde, a outros negócios informais-ilegais. Entre altos e baixos, os conflitos armados passaram a envolver policiais também que matam e morrem neles.

Falta de investigação, registros mal feitos e ausência de transparência nas operações policiais e militares no Rio de Janeiro continuam aumentando o número de casos de homicídios sem resolução. Policiais apresentam seus próprios 'fatos' como se fossem o que ocorreu, moradores desmentem os policiais e anos se passam sem que os responsáveis pelas mortes sejam apontados, processados, punidos. Para os moradores, restam os gritos roucos para ouvidos moucos: 'queremos justiça'. Para os policiais, fica a impossibilidade de melhorar o policiamento e as operações especiais porque não há evidências para orientar essas práticas e avaliar os agentes envolvidos. Continua a prevalecer a improvisação e a incapacidade de responder aos imprevistos seguindo os protocolos e normas da corporação. Este é o nó que mantém o policiamento em níveis baixos de eficácia e operações que resultam em mortes de jovens, apenas recém-saídos de um baile, ou de profissionais da segurança surpreendidos com tiroteios. Cabe perguntar: onde está o sistema de gerenciamento de risco e o planejamento da ação que deixe claro para os moradores do local e os próprios policiais quais são as regras a serem seguidas?

Guerra foi o nome dado a esses conflitos intermitentes porém intermináveis. Mas que guerra é essa? Não começou com uma declaração e não vai terminar com um acordo assinado entre as partes. Recentes estudos internacionais falam dessa guerra irregular, selvagem, sem limites institucionais que se espalhou pelo mundo na forma do que se denominou Transnational Organized Crime (TOC), baseada nos negócios ilegais que trazem muito ganho quando garantem a impunidade dos seus agentes, ou ainda na forma de organizações fundamentalistas baseadas no terror contra outras religiões, justificadas pela verdade incontestável das suas crenças $^{3,4}$. O que há de comum nessas organizações com características tão diferentes, é o uso de armas leves - que podem ser colocadas nas mãos dos muito jovens, até mesmo crianças - assim como a facilidade com que ultrapassam as fronteiras porosas entre países com institucionalidade fraca ou falha ${ }^{5}$. Fazem parte do processo de globalização, aquele que poderia ser chamado de globalização das trevas ou infraglobalização por ser pouco visível, mas destruidor do respeito às leis e aos direitos, ou seja, ao estado democrático de direito. Muitos Estados constituídos também praticam formas de terrorismo e de interferência em países cujas fronteiras tornam porosas. Porém, no Brasil, não enfrentamos no momento esse tipo de ameaça externa de Estados poderosos. Mas enfrentamos, sim, os efeitos desagregadores do TOC.

Como em toda a guerra, não se trata apenas de questão militar, mas também de saúde. Além do número de mortos e feridos que oneram e entravam o sistema de saúde pública, doenças infecciosas e psíquicas, estas relativas ao estresse e ao medo, são efeitos colaterais da guerra que acaba por influir nos seus resultados 
e na eternização dos combates pelo aumento do ódio e da vingança. Nas 'guerras' há vários medos: o dos combatentes, o dos civis afetados diretamente pelos confrontos armados, o dos moradores das cidades difusamente afetados por sensações e construções advindas dos confrontos entre grupos distintos e da criminalidade urbana comum, isto é, furtos, assaltos, agressões, latrocínios, assassinatos interpessoais. Esses medos diversos não são apenas emoções instintivas que se expressam fisicamente na fisionomia, na tensão muscular, no suor frio e em outras manifestações corporais do medo, mas são produzidos ou construídos pelos significados socialmente remetidos às emoções e aos objetos considerados como a fonte do medo. Entretanto, apenas na experiência direta do ataque violento ou da ameaça de morte, os sintomas físicos se fazem visíveis e pode-se falar de algo próximo à emoção básica do medo, embora mesmo nessa situação de perigo à vida da pessoa haja lugar para a definição do que é a ameaça, quem ou o que ameaça e para a construção da resposta a ela. Nas demais experiências, é a construção social do medo, da situação de ameaça, do objeto ameaçador que predomina sobre a emoção básica, quase impossível de ser percebida. Em qualquer caso, não há uma resposta inata ao medo, que anda sempre misturado a outras emoções - desde a raiva, passando pela desconfiança e a insegurança -, cujas reações podem variar da paralisia até a fuga célere da situação. Negar o medo é deixar a pessoa entregue a emoções que ela não controla.

O medo dos combatentes tem sido pouco pensado nas políticas de segurança, a não ser muito recentemente para incluir os efeitos da síndrome do estresse pós-traumático entre policiais como um dos elementos importantes nessa política. O medo dos que moram nas áreas conflagradas - dentro de favelas dominadas por traficantes ou milicianos e no entorno delas - é outra área pouco examinada para pensar uma política de segurança pública mais eficaz. Certamente ela é crucial para entendermos a política que está na base da segurança pública, ou seja, o apoio dado a um dos lados das batalhas violentas entre os grupos ou comandos de traficantes, mas principalmente do conflito armado entre policiais e 'bandidos'. A disposição para a luta depende muito da força moral, pouco valorizada, ou do julgamento feito pelos moradores sobre os protagonistas dessas guerras. O medo mais difícil de deixar de ser meramente reativo para se transformar em proativo é o medo difuso que não afeta apenas as pessoas diretamente envolvidas em situações de violência. Como não depende apenas das experiências vividas por elas, o medo fica mais marcado pelas ideologias, pelas mensagens transmitidas na mídia tradicional, hoje parcialmente controlada por igrejas neopentecostais, assim como nos novos meios de comunicação.

$\mathrm{Na}$ verdade, está mais do que na hora de fazer valer as propostas da política de proximidade para melhorar as relações entre a polícia e as favelas. Ouvir o que têm a dizer os moradores deveria ser parte do policiamento ostensivo, com a aplicação das práticas adotadas no policiamento orientado para a solução de problemas que tantos bons resultados já obteve em cidades nos Estados Unidos onde também se enfrenta a violência entre gangues. Só assim será possível superar a repetida cena de acusações mútuas entre policiais e moradores. As organizações da segurança devem perseguir a transparência e a legitimidade para que possam trabalhar com mais eficácia e menos violência, ou seja, menos mortes desnecessárias e inaceitáveis.

É preciso, porém, repensar a interpretação dada por movimentos sociais que denunciam o extermínio dos jovens negros no Brasil. A afirmação é feita como se houvesse uma política oficial, explícita e persistente, de matar jovens negros, uma política racista e de crime contra a humanidade. Mas nenhuma política de extermínio foi implementada aqui. No máximo, há efeitos não intencionais de políticas repressivas praticadas por policiais mal preparados em governos dirigidos por políticos indiferentes ao destino dos cidadãos mais pobres. As palavras têm importância simbólica. Ao insistir que se trata de genocídio não se está, sem intento, impossibilitando relações menos conflitivas entre moradores, jovens ou não, e policiais?

Não se pode negar o morticínio de homens jovens negros no Brasil. Mais do que nunca, falar hoje das mortes cometidas por agentes do Estado é de crucial importância para termos uma polícia comprometida com o estado de direito que não abuse do uso da força, especialmente das armas letais que legalmente portam. A participação das polícias nessas mortes representa uma vergonha para todos os que querem o 
estado de direito consolidado no país. No entanto, falar apenas delas provoca não só uma grave distorção dos fatos, mas também o fortalecimento de atitudes reativas de policiais que se sentem injustamente culpados pelas mortes que eles sabem ter outros perpetradores. As denúncias assim postas, feitas há tantos anos, conseguiram resolver o problema da segurança pública? O peso das culpas, postas nos ombros dos policiais que já gritam que só a polícia não resolve, ficou insuportável.

Deve-se, sim, enfrentar o contexto social em que jovens se matam mutuamente por participarem de bocas de fumo, galeras ou facções que criam um inimigo odiado e desumanizado na figura do 'alemão', que mora na área dominada pela outra facção. A tese do genocídio negro, embora se baseie em dados estatísticos que mostram maior concentração de homicídios entre os negros no Brasil, não considera as diferenças de local de moradia, escolaridade, renda familiar e outras variáveis. Mas pode estar estimulando o ódio aos brancos, especialmente os mais próximos e acessíveis, os de classe média espalhados por todas as áreas de planejamento da cidade do Rio de Janeiro, inclusive nos subúrbios cariocas onde estão $50 \%$ das favelas e onde a incidência de roubos e homicídios é maior do que nas demais áreas. Ou seja, as maiores vítimas dos crimes violentos estão nessa área que concentram os pobres e grande parte da classe média baixa.

É a hora de fazer a crítica da polarização em curso no país, dividindo-o de cabo a rabo. No calor das emoções, foi-se do agônico para o antagônico, em que a possibilidade de escutar o outro, de ter compaixão pelo seu sofrimento, desapareceu. Mas haverá um abismo intransponível entre policiais e favelados, brancos e negros, elite e povo, classe média e pobres? Certamente não dentro das favelas, onde também há pessoas de classe média, brancos e de escolaridade mais alta, nem muito menos onde favela e asfalto não mais se distinguem visualmente, como nos subúrbios.

Para reformar a segurança pública no país, será preciso desconstruir falsas polaridades e parar de estimular ódios porque, segundo inúmeros estudos internacionais, é a construção do outro como inimigo desumanizado que motiva um ser humano a se armar e matar outros seres humanos, de diferentes religiões, raças, ou classes de escolaridade e rendimento, isto é classes sociais não antagônicas. Nos anos pesquisando jovens vulneráveis do Rio de Janeiro, deparei-me com a definição de um inimigo ameaçador que justifica os ataques letais contra ele. É com base nessa construção imaginária que os meninos da favela se transformam em traficantes soldados. É com ela que os policiais, fardados ou não, se transformam em policiais guerreiros. Para isso, contam com a simbologia e a eficácia de armas de fogo que matam rápida e eficazmente, dando aos que as usam a sensação de poder sobre a vida e a morte dos outros. Nada mais atraente para os homens em busca de afirmação e poder. Nada mais ilusório, pois quem usa armas é alvo preferencial de tiros. Até que ponto a tese do genocídio negro não estimula o ódio e a agressividade entre negros 'vítimas' do racismo de policiais e os policiais negros apresentados como seus algozes?

Portanto, é preciso pensar em projetos para ganhar os jovens atraídos pelos comandos de crime organizado que atuam hoje em todo o território nacional desmantelando a atração exercida por este importante ator nas trevas das atividades empresariais. As armas de fogo, com a posse das quais os jovens vulneráveis prosseguem se sentindo poderosos e protegidos pela organização criminosa, continuaram entrando no país. As drogas, com as quais tantos se compensam pelas frustrações e estresses de viver numa sociedade altamente desigual e competitiva, continuaram sendo vendidas ilegalmente dando enormes lucros para os seus empreendedores. Nada foi feito para mudar essa atração pelo negócio ilegal altamente lucrativo. Enquanto nada for feito, vamos ficar investindo muito para ver todo o gasto ir embora pelo ralo.

Como já afirmei anteriormente, podemos enfrentar a disseminação do etos guerreiro entre nós com iniciativas, consolidando a segurança pública baseada na cidadania.

1. Precisamos exigir mais controle e investigação sobre a circulação das armas de fogo no país. Como não se montou uma força-tarefa para investigar os comerciantes legais e ilegais de armas ou uma 
Operação Lei Desarmada para fiscalizar os que as portam em locais públicos? São elas que trazem enorme prejuízo ao país em vidas e horas de trabalho perdidas, agravos resultantes do estresse pós-traumático para os quais o Sistema Único de Saúde (SUS) ainda não tem preparo nem verba suficiente por causa dos gastos com os feridos e mortos por elas.

2. Carecemos de ações culturais e educativas contínuas para desconstruir o etos guerreiro, responsável pelo uso impulsivo que fazem das armas jovens e policiais. É o maior desafio, pois o medo de morrer armou mãos e cabeças e justificam as mortes dos inimigos imaginários. Os efeitos, inclusive na formação subjetiva dos que se tornam agentes, mas também vítimas da violência armada, só pode ser enfrentado com a cooperação de todos: agentes da segurança, saúde e educação, artistas, jornalistas, técnicos de diversas áreas, demais profissionais que lidam com público.

3. Devemos mudar a política de drogas no país que demoniza algumas substâncias enquanto outras ainda mais danosas são legalmente comercializadas. Isso estigmatiza o usuário de drogas a ponto de tornar justificável a sua perseguição e morte por grupos extralegais de segurança e policiais. Isso transforma o traficante num criminoso de alta periculosidade, pois o tráfico de drogas é crime hediondo e inafiançável como o terrorismo, embora seja basicamente o comércio de mercadoria desejada por consumidores. Não é a droga que mata, é a proibição que incentiva a corrida armamentista entre grupos de traficantes e a guerra entre estes e policiais, aumentando o medo e a insegurança que tornam desejáveis grupos extralegais e paramilitares. Com mais investigação e punição dos responsáveis, a visão apocalíptica que moradores de várias ricas cidades brasileiras têm da situação vivida nas suas ruas cotidianamente também poderia ser amenizada.

4. Os encontros de cadáveres, os desaparecidos, as mortes mal definidas ou as mortes por causa desconhecida vão se acumulando em estranhos escaninhos junto com as estatísticas oficiais dos homicídios. Deveriam ser eliminadas substituindo-as por mortes com indícios de crime ou mortes sem indícios de crime, duas categorias que ajudariam a investigação posterior. Sim, é preciso uma força-tarefa urgente para esclarecer todas essas mortes nunca ou mal investigadas que só fazem estimular novos assassinatos. Já temos o mapa delas, pois a sua ecologia é muito reveladora: basta acompanhar a precariedade da cidadania nos diferentes municípios que compõem a região metropolitana e, dentro do município do Rio, os bairros em que mortes violentas tomam proporções assustadoras. É neles que se guerreiam milícias e comandos de traficantes e onde agem os policiais corruptos.

Finalmente, gostaria de lembrar que, no mundo todo, os estudos estratégicos, de raiz militar, foram sendo substituídos pelos estudos de segurança pública entendidos de forma mais abrangente, fundamentalmente política. Em qualquer missão de paz, preconiza-se dimensionar o alcance da ideia de paz para valores e políticas em curso, assim como o seu lugar no debate cognitivo e a importância que a não violência tem nos processos de transformação política. Há que participar ativamente desse debate nas escolas, na mídia, no espaço público de discussão. Como aumentar a capacidade de cooperação e de negociação de conflitos na cidade? Será meramente pelo controle das armas que aqui chegam, sem dúvida nenhuma eficaz para diminuir os homicídios, que chegaremos à pacificação? Ou será uma mudança cultural mais profunda que busca desenvolver disposições não violentas, não guerreiras, para a vida numa democracia constitucional em que a cooperação, a mediação e a negociação de conflitos são pilares imprescindíveis? A dimensão política e psíquica mais uma vez fica evidente.

A paz precisa ser entendida como um modo de vida ou uma cultura, que se obtém, segundo John Dewey ${ }^{6}$, um dos teóricos da paz, na socialização do bom cidadão. Este começa com o bom vizinho e o bom amigo, mas 
é também aquele que contribui para o bem-estar coletivo e não é mero carona ou eterna vítima dos outros. São as disposições ou atitudes mentais que dissolvem as chamas do ódio e da suspeita os ingredientes indispensáveis nessa construção do respeito, da responsabilidade, da cooperação e do diálogo ${ }^{7}$. As formas autoritárias de poder e a repressão injustificada, denominada de covardia pelos cariocas mais humildes, ao contrário, trazem como resultado a conformidade forçada, o silêncio reprimido e o medo no diferencial da capacidade de defesa de cada segmento da população.

Só que esse diferencial inclui a grande capacidade de agressão violenta que hoje as facções criminosas têm, desde as favelas da cidade onde as relações são profundamente assimétricas entre os traficantes e assaltantes armados e os demais moradores: estudantes, trabalhadores, donas de casa, crianças e idosos desarmados. As barricadas que constroem dentro delas impedem o acesso à escola, ao posto de saúde, à cidade onde poderiam usufruir de equipamentos inexistentes no local de moradia. As barricadas são também a concretização dos entraves sempre postos ao entendimento mútuo pelo uso da palavra e não da arma. Proteger as escolas e demais equipamentos locais, assim como as entradas e saídas das favelas trará uma mensagem de paz facilmente compreensível e aceita pelos moradores das que são dominadas por facções bem armadas.

Não se pode esquecer nunca que paz, como ausência de guerra, significa ausência de assimetrias e dominação autoritária, seja do Estado, seja da facção criminosa. Fazer a paz nas favelas é desmantelar essa insuportável assimetria no território dominado, pois não é de bom alvitre substituir uma dominação autoritária por outra ainda mais refratária à lei maior e, portanto, a direitos do cidadão. 'Paz, Justiça e Liberdade', lema do CV (Comando Vermelho) copiado pelo PCC (Primeiro Comando da Capital), termina na decisão dos chefes sobre a vida e a morte dos que venham a atrapalhar os negócios da quadrilha. $\mathrm{O}$ verdadeiro farol da ação dessas facções é 'O crime fortalece o crime’ e quem quer que bloqueie esta corrente será impiedosamente punido. Nisso, infelizmente, não há consenso entre os estudiosos da segurança pública.

\section{Referências}

1. Zaluar A. Condomínio do diabo. Rio de Janeiro: Revan; 1994.

2. Zaluar A. Integração perversa: pobreza e tráfico de drogas. Rio de Janeiro: FGV; 2004.

3. Nasser R, Moraes $R$, editores. Brasil e a segurança no seu entorno estratégico: América do Sul e o Atlântico Sul. Brasilia (DF): IPEA; 2004. Sain M, Games N. Capítulo 5, Tendências e desafios do crime organizado na América Latina; p. 119-44.

4. Banfield J. Crime and conflict: the new challenge for peacebuilding. International Alert Organization. 2014 [citado em 10 out. 2018]. Disponível em: https://www.international-alert.org/sites/default/files/ CVI CrimeConflict EN 2014 0.pdf

5. The Geneva Declaration Secretariat. Global burden of armed violence, 2015: every body counts. Geneva: Cambridge University Press; 2015.

6. Dewey J. The schools as a means of developing a social consciousness and social ideals in children. Journal of Social Forces. 1923;1(5):513-517. doi: https://doi.org/10.2307/3005121

7. Howlett CF, Cohan A. John Dewey: His role in public scholarship to educate for peace. Social and Education History. 2016;5(3);203-222. doi: http://dx.doi.org/10.17583/hse.2016.2097 